\title{
Sperm storage in the reproductive tract of the female Japanese long-fingered bat, Miniopterus schreibersii fuliginosus
}

\author{
T. Mōri and T. A. Uchida \\ Zoological Laboratory, Faculty of Agriculture, Kyushu University, Fukuoka 812, Japan
}

\begin{abstract}
Summary. In the Japanese long-fingered bat, Miniopterus schreibersii fuliginosus, spermatozoa in contact with the microvilli of non-ciliated cells in folds in the uterotubal junction appeared normal, while spermatozoa remaining in the uterus degenerated and were engulfed by a massive invasion of polymorphonuclear leucocytes. No leucocytes were seen in the uterotubal junction area. It is suggested that the spermatozoa in this area are being stored, probably until ovulation occurs.
\end{abstract}

\section{Introduction}

In such temperate vespertilionine bats (family Vespertilionidae) as Pipistrellus abramus (Hiraiwa \& Uchida, 1956), P. pipistrellus (Racey \& Potts, 1970) and Myotis lucifugus (Wimsatt, Krutzsch \& Napolitano, 1966) spermatozoa introduced into the uterus in the autumn fertilize the ova released in the spring after survival in the uterus for a prolonged period (Racey, 1975, 1979). In the long-fingered bat, Miniopterus schreibersii fuliginosus, which belongs to the subfamily Miniopterinae, however, it has been believed that copulation in mid-October is followed closely by ovulation and fertilization, and that the single ovum discharged from the left ovary only is fertilized immediately although implantation is delayed for a few months (Uchida, 1957). The California leaf-nosed bat, Macrotus californicus is another rare example of such a delayed development (Bradshaw, 1962). However, examination of mated specimens kept in the laboratory and isolated from males after capture showed that some females had not ovulated after copulation, and spermatozoa in these females were presumably being stored in the reproductive tract. This study was therefore carried out to investigate sperm storage and the fate of spermatozoa in long-fingered bats.

\section{Materials and Methods}

Adult female long-fingered bats (M. s. fuliginosus) were collected at Ibarayama-haikō (an abandoned mine) in the Fukuoka Prefecture and Ohse-dó Cave in the Kumamoto Prefecture in mid-October of 1969-1977. The 29 mated animals were kept healthy in captivity for 1-6 days before use in this study. The reproductive tracts were removed and the tissues promptly placed for 3-6 h in cold 3\% glutaraldehyde in $0.2 \mathrm{M}$-phosphate buffer (pH 7.4). After being thoroughly rinsed with $0.2 \mathrm{M}$-phosphate buffer $(\mathrm{pH} 7.4)$, the tissues were post-fixed with $1 \%$ osmium

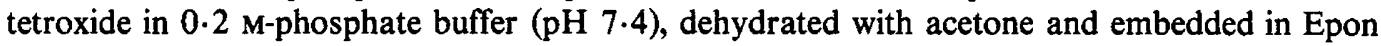
812. Thick sections $(1.5 \mu \mathrm{m})$ were stained with toluidine blue and examined with a light microscope. Thin sections $(60 \mathrm{~nm})$ for electron microscopy were doubly stained with uranyl acetate and lead citrate, and examined with an Hitachi HS-9 electron microscope. For scanning electron microscopy, a right uterotubal junction was fixed with $3 \%$ glutaraldehyde in $0.2 \mathrm{M}$-phosphate buffer ( $\mathrm{pH} 7.4$ ) and dried by the critical-point method and viewed in an Hitachi SSM-2. 


\section{Results}

Spermatozoa in long-fingered bats were found in the uterotubal junction (UTJ) and in the lumen and glands of the uterus. Since the spermatozoa reaching the UTJ survive until ovulation, judged by their intact appearance, while spermatozoa retained in the uterus degenerate, the spermatozoa in these two situations are described separately. The following observations were consistent for all specimens examined.

\section{Morphology of surviving spermatozoa in the uterotubal junction}

Generally the UTJ refers to the region where the oviduct enters the uterus. In the bat, this was divided into two parts, the extreme caudal portion of the isthmus surrounded by the uterine wall (intramural part of the UTJ) and the well developed colliculus tubaricus which is a projection of the oviduct into the uterine lumen (Text-fig. 1); the interior of the colliculus tubaricus had longitudinally parallel folds which become the longitudinal folds of the intramural part of the UTJ (Pl. 1, Fig. 1). When the entrance of the colliculus tubaricus was viewed from the uterine side, a rosette-like structure was observed with 4-5 leaves (Pl. 1, Fig. 2). After

\section{PLATES 1-4}

Abbreviations: A, acrosome; $\mathrm{C}$, cilia; $\mathrm{Cc}$, ciliated cell; $\mathrm{Ct}$, colliculus tubaricus; $\mathrm{D}$, diverticula; De, debris; F, folds of colliculus tubaricus; Gc, glandular cell; Gl, granules of leucocyte; I, isthmus; Ip, intramural part; L, leucocyte; Lc, lumen of colliculus tubaricus; Lct, leaves of colliculus tubaricus; Lip, lumen of intramural part; $\mathbf{M}$, mitochondrion; $\mathbf{M i}$, microvilli of glandular cell; $N$, nucleus; Nc, non-ciliated cell; $P$, phagosomes; S, spermatozoa; Sd, small dense bodies; Sm, slender microvilli of ciliated cell; Sn, sperm nucleus; St, sperm tail; Stm, stout microvilli; $\mathrm{U}$, uterus; $\mathrm{Ug}$, uterine gland; $\mathrm{U}$, uterine lumen; $\mathrm{Utj}$, uterotubal junction.

\section{PLATE 1}

Fig. 1. Longitudinal section through the left uterotubal junction, showing the intramural part and well developed colliculus tubaricus in which longitudinally parallel folds are present. Among the longitudinal folds of the intramural part there are narrow, deep diverticula (arrowheads). The white line indicates the plane of section in Fig. 4.

Fig. 2. Scanning electron micrograph of the colliculus tubaricus showing its rosette-like structure with 4-5 leaves surrounding the lumen.

Fig. 3. Spermatozoa in the lumen of the colliculus tubaricus. They appear to be free in the lumen or resting against the border of the epithelial cells.

Fig. 4. Cross-section of the intramural part through the section indicated in Fig. 1, showing two diverticula containing many spermatozoa.

\section{PLATE 2}

Fig. 5. Electron micrograph showing intact spermatozoa with parallel orientation resting between microvilli of the epithelial cells at the inner part of the diverticula. Compare them with epididymal spermatozoa (inset). The non-ciliated cells have stout microvilli, while the ciliated cells have slender ones.

\section{PLATE 3}

Figs 6-8. Electron micrographs of the degenerating spermatozoa in the glandular cavity. Fig. 6. Spermatozoa which seem to be intact in appearance have no contact with the microvilli of the glandular cells. Fig. 7. Fusion (arrow-heads) of the plasma and outer acrosomal membranes is a characteristic feature of the degenerating spermatozoon. Fig. 8. The remnants of the spermatozoa are seen free in the cavity.

Fig. 9. Electron micrograph of the degenerating spermatozoa and leucocytes in the uterine lumen. 
PLATE 1
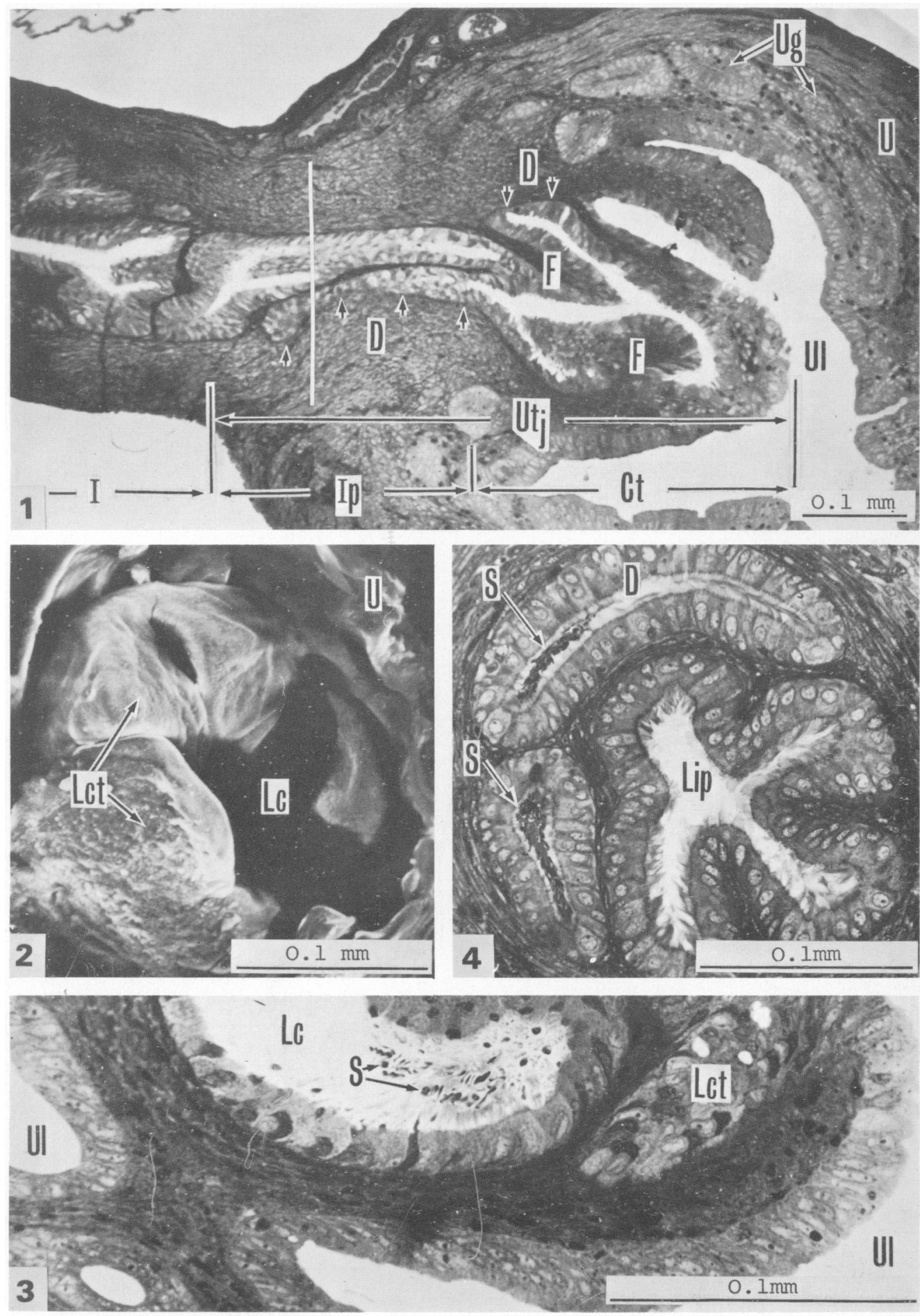

(Facing p.430) 
PLATE 2

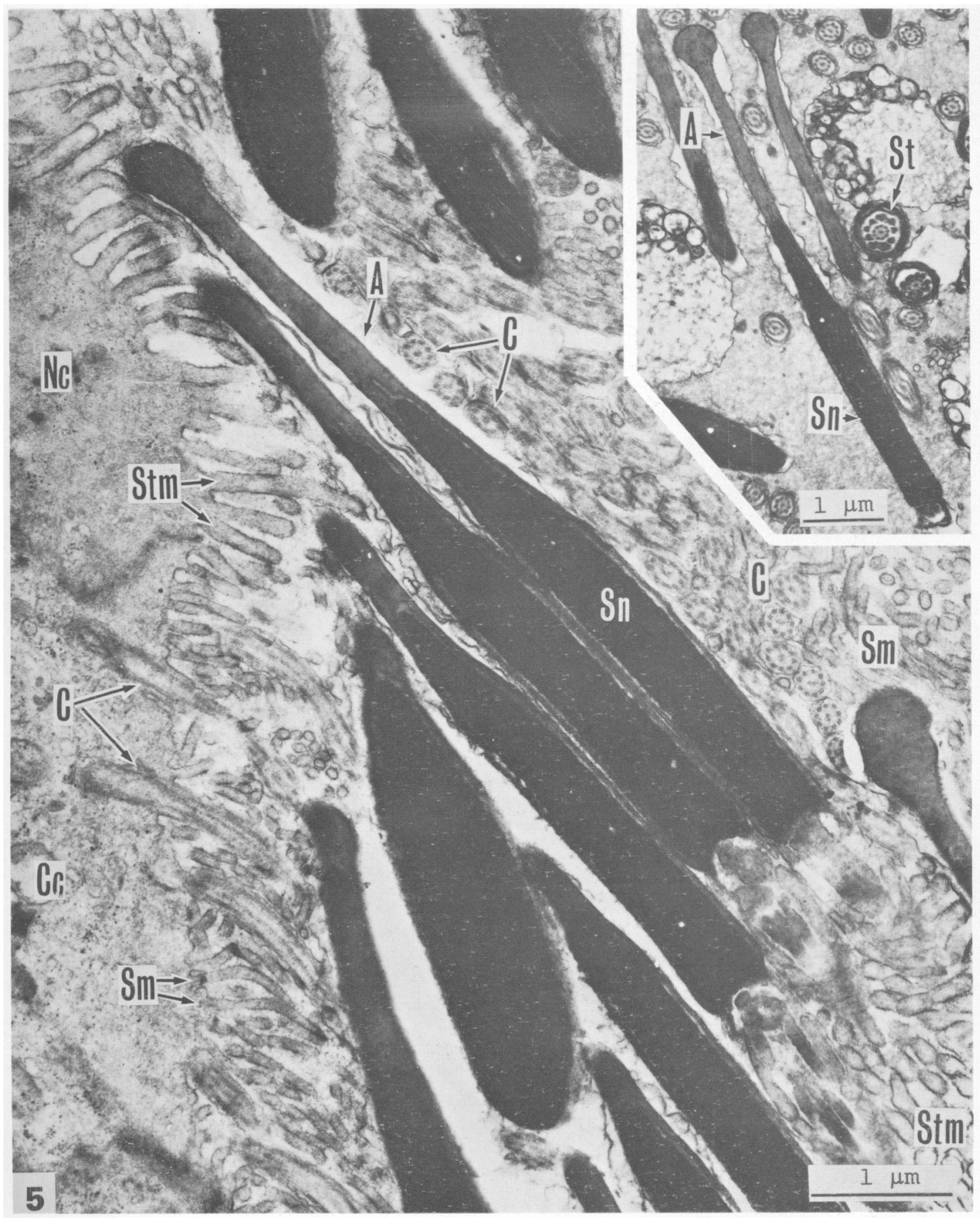




\section{PLATE 3}
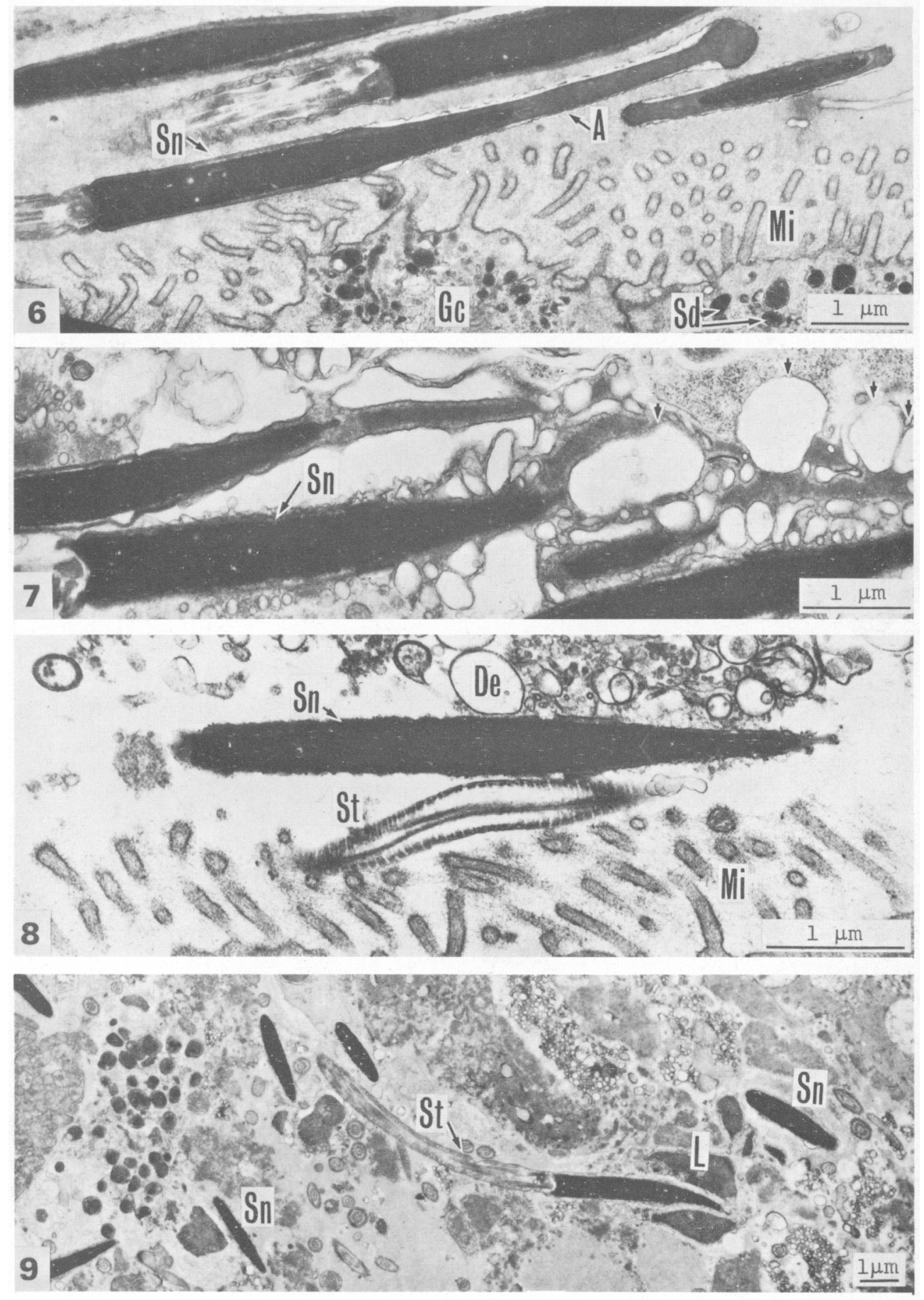


\section{PLATE 4}
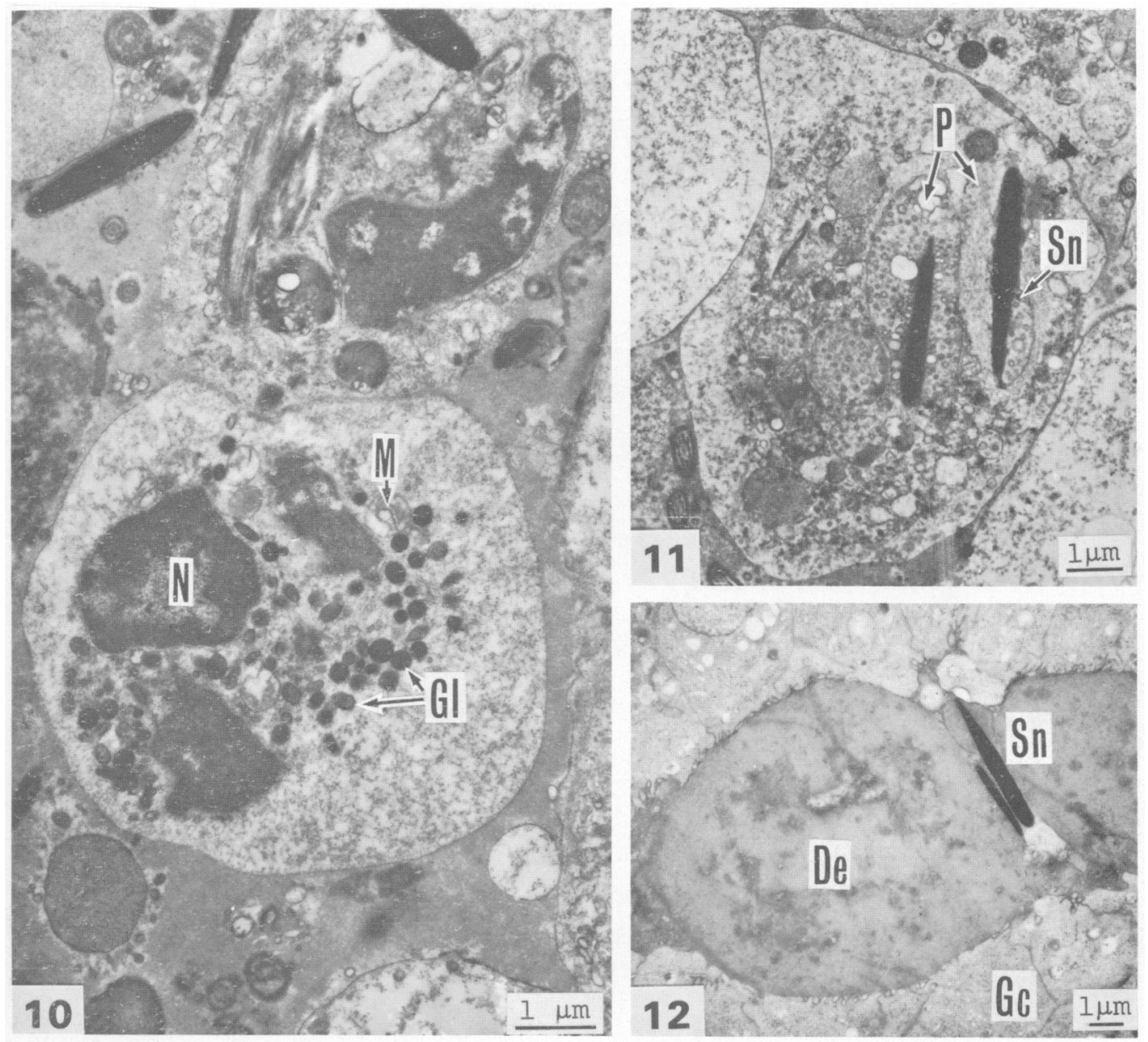

Figs 10-12. Electron micrographs of polymorphonuclear leucocytes in the glandular cavity.

Fig. 10. Leucocyte not engulfing spermatozoa. A lobulated nucleus and many granules are recognized. Fig. 11. Leucocyte losing granules, but with phagosomes including a sperm head which is devoid of acrosome. Fig. 12. Debris of the residual bodies including the indigestible sperm nuclei in the glandular cavity. 


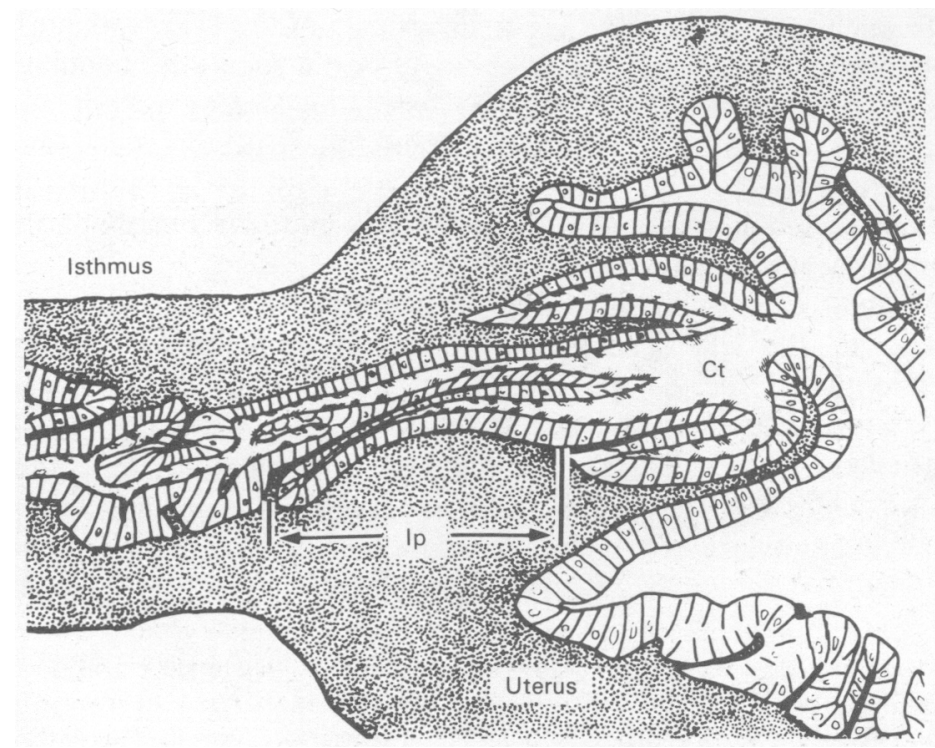

Text-fig. 1. Diagram of the uterotubal junction, consisting of the intramural part (Ip) and colliculus tubaricus $(\mathrm{Ct})$, of the Japanese long-fingered bat.

copulation, the surviving spermatozoa were concentrated in the lumina of both the colliculus tubaricus (Pl. 1, Fig. 3) and the intramural part of the UTJ (Pl. 1, Fig. 4), where most spermatozoa appeared to be free in the lumina or merely resting against the microvilli and cilia of the epithelial cells.

Among the longitudinal folds of the intramural part of the UTJ, narrow, deep diverticula were present (Pl. 1, Fig. 1) and sometimes contained large numbers of spermatozoa (Pl. 1, Fig. 4). The epithelium at the base of the folds of the intramural portion of the UTJ consisted predominantly of non-ciliated cells which had stout microvilli (about $130 \mathrm{~nm}$ in diameter) which were different from the more slender ones (about $90 \mathrm{~nm}$ diameter) of the ciliated cells present (Pl. 2, Fig. 5). These features seemed to be characteristic of the epithelial cells in the intramural portion of the UTJ, in contrast to the epithelial cells in the other parts of oviduct which all had scattered slender microvilli.

The tissue of the colliculus tubaricus was free of uterine glands, and contained a large amount of connective tissue. Migration of leucocytes into the connective tissue occurred only on the side where the epithelium faced towards the uterine lumen, and we never observed invasion of leucocytes into the connective tissue of the epithelium facing to the lumen of the colliculus tubaricus. No secretory granules, as are observed in non-ciliated epithelial cells of the isthmus and ampulla, were seen in the epithelia of the UTJ.

At the inner part of the diverticula formed by folds of the intramural part of the UTJ, clumps of spermatozoa with parallel orientation rested between microvilli of the epithelial cells. No special morphological modifications of the spermatozoa were recognized compared with epididymal spermatozoa (Pl. 2, Fig. 5 and inset).

\section{Death of spermatozoa and infiltration of leucocytes in the uterus}

The uterine glands of this bat are of the simple tubular type. When they begin to function during oestrus, the cells enlarge and the cavities increase in depth. The activity of the uterine glands is at its maximum soon after ovulation.

Although the spermatozoa appeared to be clustered with their heads orientated towards the base of the glandular cavity, a mutual association between the spermatozoa and the microvilli of 
the epithelial cells, such as was observed in the diverticula of the UTJ, was not seen (Pl. 3, Fig. 6). Regression of spermatozoa in the glandular cavity began soon after copulation, and the first change occurred in the acrosome (Pl. 3, Fig. 7). Disruption of the acrosome was characterized by fusion of the plasma and outer acrosomal membranes, accompanied by leakage of the acrosomal substance into the glandular cavity. Eventually the fragments of spermatozoa remained free in the glandular cavity (Pl. 3, Fig. 8). Spermatozoa remaining free in the uterine lumen similarly underwent degeneration (Pl. 3, Fig. 9).

When the glandular cavity contained a large number of the spermatozoa, the walls of the uterine glands became the site of a massive invasion of neutrophilic, polymorphonuclear leucocytes with a lobulated nucleus and cytoplasm having many fine granules (Pl. 4, Fig. 10). Bodies limited by a membrane and containing the indigestible chromatin of sperm heads could be recognized in leucocytes ( $\mathrm{Pl}$. 4, Fig. 11), and eventually only debris of the residual bodies remained in the glandular cavity (Pl. 4, Fig. 12).

\section{Discussion}

In the Japanese house bat, Pipistrellus abramus, copulation takes place in autumn, and ovulation and fertilization occur in spring; therefore spermatozoa survive in the uterus for a prolonged period (Hiraiwa \& Uchida, 1956). The uterus is distended greatly by semen, and spermatozoa are arranged with their heads orientated towards and in contact with the uterine epithelium (Nakano, 1928; Hiraiwa \& Uchida, 1955). Racey \& Potts (1970) have shown a similar relationship between the uterine microvilli and plasma membranes of adjacent spermatozoa in the European pipistrelle, Pipistrellus pipistrellus.

In the Indian pipistrelle, Pipistrellus ceylonicus chrysothrix, and greater yellow bat, Scotophilus heathi, however, surviving spermatozoa are stored in both the uterus and oviduct (Gopalakrishna \& Madhavan, 1971; Krishna \& Dominic, 1978). In the flat-headed bats, Tylonycteris pachypus and $T$. robustula, comparatively few spermatozoa are found in the uterus and most occur in the oviduct where they are orientated with their heads towards the epithelium (Medway, 1972). The heads of a few of these spermatozoa are embedded in the microvilli or cilia of the oviduct epithelial cells, but those of most spermatozoa are situated in indentations in the luminal surface of the epithelial cells (Racey, Suzuki \& Medway, 1975). In the long-fingered bats in the present study the site of sperm storage in the female reproductive tract was strictly limited to the UTJ, and we suggest that the close relationship between sperm heads and adjacent epithelial cells prolongs the survival of these spermatozoa.

It is believed that an important function of leucocytes appearing in the uterine lumen after copulation is probably to eliminate dead or excess spermatozoa by phagocytosis (Austin, 1957; Yanagimachi \& Chang, 1963; Zamboni, 1972). Therefore, the fact that the infiltration of leucocytes does not occur in P. abramus, the uterus of which is capable of storing spermatozoa throughout winter (Uchida \& Möri, 1974), is regarded as an adaptive character in this species. Furthermore, in the temperate vespertilionine bats ( $P$. pipistrellus, Nyctalus noctula, Myotis nattereri and $M$. daubentoni) and rhinolophid bats (Rhinolophus ferrumequinum and $R$. hipposideros) examined so far, Racey $(1975,1979)$ has reported that few leucocytes are found in the female reproductive tracts. Hunter, Johnson, Barker, Fahning \& Schultz (1971) have shown that a protein isolated from the seminal vesicle of $M$. lucifugus, in which sperm storage in the uterus is confirmed, seems to inhibit both uterine motility and the phagocytic system. In $M$. $s$. fuliginosus a large number of leucocytes was usually found in the uterus after copulation, but there was no infiltration of leucocytes into the UTJ. The mechanism preventing the passage of leucocytes through the UTJ is unclear; anatomical studies of the UTJ in many species, however, indicate that a valve-like structure is present which prevents simple continuity of the lumen between the uterus and oviduct (Andersen, 1928; Leonard \& Perlman, 1949; Edger \& Asdell, 1960; Hafez \& Black, 1969). 
In $P$. abramus, large quantities of semen cause the uterus to swell without the formation of a vaginal plug. In $M$. s. fuliginosus, however, the volume of semen introduced into the uterine lumen is less because most of the semen ejaculated into the female tract coagulates in the vagina (unpublished observations); almost all the uterine spermatozoa are deposited in the uterine glands, and are thus accessible to early phagocytic activity by leucocytes. As in the rat and mouse (Austin, 1957), this fate for spermatozoa is consistent with them not being needed for fertilization.

We thank Professor E. W. Jameson, Jr, University of California, for comments on the manuscript and Dr P. A. Racey, University of Aberdeen, for advice and encouragement in the course of this study.

\section{References}

Andersen, D.H. (1928) Comparative anatomy of the tube-uterine junction. Histology and physiology in the sow. Am. J. Anat. 42, 255-305.

Austin, C.R. (1957) Fate of spermatozoa in the uterus of the mouse and rat. J. Endocr. 14, 335-342.

Bradshaw, G.V.R. (1962) Reproductive cycle of the California leaf-nosed bat, Macrotus californicus. Science, N.Y. 136, 645-646.

Edger, D.G. \& Asdell, S.A. (1960) Spermatozoa in the female genital tract. J. Endocr. 21, 321-326.

Gopalakrishna, A. \& Madhavan, A. (1971) Survival of spermatozoa in the female genital tract of the Indian vespertilionid bat, Pipistrellus ceylonicus chrysothrix (Wroughton). Proc. Ind. Acad. Sci. Ser. B. 73, 43-49.

Hafez, E.S.E. \& Black, D.L. (1969) The mammalian uterotubal junction. In The Mammalian Oviduct, pp. 85-126. Eds E. S. E. Hafez \& R. J. Blandau. University of Chicago Press, Chicago.

Hiraiwa, Y.K. \& Uchida, T. (1955) Fertilization in the bat, Pipistrellus abramus abramus (Temminck). II. On the properties of semen stored in the uterus. Sci. Bull. Fac. Agr. Kyushu Univ. 15, 255-266. [In Japanese with English summary.]

Hiraiwa, Y.K. \& Uchida, T. (1956) Fertilization in the bat, Pipistrellus abramus abramus (Temminck). III. Fertilizing capacity of spermatozoa stored in the uterus after the copulation in the fall. Sci. Bull. Fac. Agr. Kyushu Univ. 15, 565-574. [In Japanese with English summary.]

Hunter, A.G., Johnson, W.L., Barker, L.D.S., Fahning, M.L. \& Schultz, R.H. (1971) Bat seminal vesicle protein: its characterization and physiological properties. J. Reprod. Fert. 24, 179-186.

Krishna, A. \& Dominic, C.J. (1978) Storage of spermatozoa in the female genital tract of the verspertilionid bat, Scotophilus heathi. J. Reprod. Fert. 54, 319-321.

Leonard, S.I. \& Perlman, P.L. (1949) Conditions effecting the passage of spermatozoa through the uterotubal junction of the rat. Anat. Rec. 104, 89. 102.

Medway, Lord (1972) Reproductive cycles of the flatheaded bats Tylonycteris pachypus and $T$. robustula (Chiroptera: Vespertilioninae) in a humid equatorial environment. Zool. J. Linn. Soc. 51, 33-61.
Nakano, O. (1928) Über die Verteilung des Glykogens bei den zyklischen Veränderungen in den Geschlechtsorganen der Fledermaus. Und über die Nahrungsaufnahme der Spermien in dem weiblichen Geschlechtswege. Folia anat. jap. 6, 777-828.

Racey, P.A. (1975) The prolonged survival of spermatozoa in bats. In The Biology of the Male Gamete, pp. 385-416. Eds J. G. Duckett \& P. A. Racey. Academic Press, London.

Racey, P.A. (1979) The prolonged storage and survival of spermatozoa in Chiroptera. J. Reprod. Fert. 56, 391-402.

Racey, P.A. \& Potts, D.M. (1970) Relationship between stored spermatozoa and the uterine epithelium in the pipistrelle bat (Pipistrellus pipistrellus). J. Reprod. Fert. 22, 57-63.

Racey, P.A., Suzuki, F. \& Medway, Lord (1975) The relationship between stored spermatozoa and the oviducal epithelium in bats of the genus Tylonycteris. In The Biology of Spermatozoa, pp. 123-133. Eds. E. S. E, Hafez \& C. G. Thibault, S. Karger, Basel.

Uchida, T.A. (1957) Fertilization and hibernation in bats. Heredity, Tokyo 11, 14-17. [In Japanese.]

Uchida, T.A. \& Möri, T. (1974) Electron microscopic analysis of the mechanism of fertilization in Chiroptera. I. Acrosomal reaction and consequence to death of the sperm in the Japanese long-fingered bat, Miniopterus schreibersi fuliginosus. Sci. Bull. Fac. Agr. Kyushu Univ. 28, 177-184. [In Japanese with English summary.]

Wimsatt, W.A., Krutzsch, P.H. \& Napolitano, L. (1966) Studies on sperm survival mechanism in the female reproductive tract of hibernating bats. I. Cytology and ultrastructure of intra-uterine spermatozoa in Myotis lucifugus. Am. J. Anat. 119, 25-60.

Yanagimachi, R. \& Chang, C. (1963) Infiltration of leucocytes into the uterine lumen of the golden hamster during the oestrous cycle and following mating. J. Reprod. Fert. 5, 389-396.

Zamboni, L. (1972) Fertilization in the mouse. In Biology of Mammalian Fertilization and Implantation, pp. 213-262. Eds K. S. Moghissi \& E. S. E. Hafez. Thomas, Springfield.

Received 3 August 1979 